\title{
Dynamic behavior of ozonation with pollutant in a countercurrent bubble column with oxygen mass transfer
}

\author{
Y.H. Chen ${ }^{\mathrm{a}}$, C.Y. Chang ${ }^{\mathrm{a} *}$, C.Y. Chiu ${ }^{\mathrm{b}}$, Y.H. Yu ${ }^{\mathrm{a}}$, P.C. Chiang ${ }^{\mathrm{a}}$, \\ Y. Ku ${ }^{\mathrm{c}}$, J.N. Chen ${ }^{\mathrm{d}}$ \\ ${ }^{a}$ Graduate Institute of Environmental Engineering, National Taiwan University, Taipei 106, Taiwan \\ ${ }^{\mathrm{b}}$ Department of Environmental Engineering, Lan-Yang Institute of Technology, I-Lan 261, Taiwan \\ ${ }^{\mathrm{c}}$ Department of Chemical Engineering, National Taiwan University of Science and Technology, Taipei 106, Taiwan \\ ${ }^{\mathrm{d}}$ Graduate Institute of Environmental Engineering, National Chiao-Tung University, Hsin-Chu 300, Taiwan
}

Received 25 April 2002; received in revised form 6 January 2003; accepted 21 February 2003

\begin{abstract}
The dynamic behavior of ozonation with pollutants in a countercurrent bubble column is studied for the model establishment. Bubble columns have been widely used for an ozonation system in the plants and laboratories. In addition, a countercurrent bubble column has been commonly recommended than a cocurrent one because it has a higher ozone transfer efficiency. Therefore, the investigation of this paper focuses on the countercurrent bubble column. As an ozonation process starts, the gas mixture of ozone and oxygen is introduced into the bottom of a column, and then transferred into the liquid. The pollutants in the wastewater are eliminated subsequently via oxidation by the dissolved ozone. There certainly exists a temporary and unsteady period before the ozonation system reaches steady state. However, available ozonation models employed to describe ozone and pollutant profiles have commonly been developed for steady state. The treating qualities of wastewater in the early stage of ozonation are usually not predicted, and the time required for the steady-state establishment remains to be determined. Moreover, oxygen mass transfer is usually neglected in previous ozonation models so that the increase of dissolved oxygen is uncertain. These information is desirable for the proper design and operation of ozonation system in a bubble column. Thus, the aim of this study is to model and investigate the dynamic processes of ozonation with pollutants including oxygen mass transfer. The dynamic axial dispersion model proposed is employed to predict the variation of the ozone, pollutant, and oxygen concentrations profiles. The validity of the model was demonstrated by comparing the predicted results with the experimental data. The $o$-cresol was chosen as the model pollutant. The temporal concentration variations of the residual $o$-cresol and dissolved oxygen in the effluent liquid, and the off-gas ozone in the free volume were measured accordingly. Furthermore, the variation of the enhancement factor of ozone and the amount of off-gas were predicted. Note that it usually needs $2-5$ hydraulic retention times to approach steady state under the conditions of this study. Further, the effects of dimensionless system parameters on the performance of the ozonation processes are examined. As a result, the proposed dynamic model of ozonation with pollutants is useful for proper prediction of the variables of an ozonation system in a countercurrent bubble column.
\end{abstract}

(C) 2003 Elsevier Science Ltd. All rights reserved.

Keywords: Ozone; Ozonation; Countercurrent bubble column; Dynamic model; Wastewater

*Corresponding author. Tel./fax: + 886-2-2363-8994.

E-mail address: cychang3@ccms.ntu.edu.tw (C.Y. Chang).

\section{Introduction}

Ozone is one of the most effective oxidants that has been widely applied in water and wastewater treatment. It is commonly produced by electrical discharge 


\begin{tabular}{|c|c|}
\hline Nomenclature & $H a_{\mathrm{A}}, H a_{\mathrm{B}}$ Hatta numbers defined as $\sqrt{k_{\mathrm{d}} D_{\mathrm{A}}} / k_{\mathrm{LA}}^{0}$, \\
\hline $\begin{array}{l}\text { specific gas-liquid interfacial area based on } \\
\text { the volume of liquid and gas }(1 / \mathrm{m})\end{array}$ & $\begin{aligned} H_{\mathrm{A}}, H_{\mathrm{O}} & \text { Henry's law constants of ozone and oxygen, } \\
& C_{\mathrm{AGi}} / C_{\mathrm{ALi}}, C_{\mathrm{OGi}} / C_{\mathrm{OLi}}(\mathrm{M} / \mathrm{M})\end{aligned}$ \\
\hline$A \quad$ cross-section area of column $\left(\mathrm{m}^{2}\right)$ & ozonation rate constant of pollutant $(1 / \mathrm{M} \mathrm{s})$ \\
\hline $\begin{array}{c}C_{\mathrm{AGi}}, C_{\mathrm{AGi} 0} \text { gas concentrations of ozone of holdup } \\
\text { and inlet gases }(\mathrm{M} \text { or } \mathrm{mg} / \mathrm{L} \text { ) }\end{array}$ & $\begin{array}{ll}k_{\mathrm{d}} & \text { self-decomposition rate constant of ozone } \\
(1 / \mathrm{s})\end{array}$ \\
\hline $\begin{array}{ll}C_{\mathrm{AGe}} & \text { gas concentration of ozone in free volume (M } \\
\text { or } \mathrm{mg} / \mathrm{L})\end{array}$ & $\begin{array}{l}k_{\mathrm{LA}}^{0}, k_{\mathrm{LO}}^{0} \text { physical liquid-phase mass transfer coeffi- } \\
\text { cients of ozone and oxygen }(\mathrm{m} / \mathrm{s})\end{array}$ \\
\hline $\begin{array}{c}C_{\mathrm{ALb}}, C_{\mathrm{ALb}, \text { eff }} \text { dissolved ozone concentrations in bulk } \\
\text { and effluent liquids }(\mathrm{M} \text { or } \mathrm{mg} / \mathrm{L} \text { ) }\end{array}$ & $\begin{array}{l}L \quad \text { liquid height of bubble column at steady state } \\
\text { (m) }\end{array}$ \\
\hline$C_{\mathrm{ALb}, \mathrm{ss}} \quad$ steady-state value of $C_{\mathrm{ALb}}(\mathrm{M}$ or $\mathrm{mg} / \mathrm{L})$ & $m_{\mathrm{STOD}}$ specific transferred ozone dosage, \\
\hline $\begin{array}{c}C_{\mathrm{ALF}}, C_{\mathrm{BLF}} \text { dissolved concentrations of ozone and } \\
\text { pollutant in liquid film }(\mathrm{M} \text { or } \mathrm{mg} / \mathrm{L})\end{array}$ & $\begin{array}{l}C_{\mathrm{AGi} 0} u_{\mathrm{G} 0} \eta_{\mathrm{OTE}} / u_{\mathrm{L}}(\mathrm{mg} / \mathrm{L}) \\
\text { dimensionless ozone self-decomposition reac- }\end{array}$ \\
\hline $\begin{array}{ll}C_{\mathrm{ALi}} & \text { dissolved ozone concentration of liquid film } \\
& \text { at gas-liquid interface }(\mathrm{M} \text { or } \mathrm{mg} / \mathrm{L})\end{array}$ & $\begin{array}{l}\text { tion rate parameter of ozone, } k_{\mathrm{d}} D_{\mathrm{A}} / k_{\mathrm{LA}}^{0^{2}} \\
\text { dimensionless pollutant ozonation reaction rate }\end{array}$ \\
\hline $\begin{array}{l}C_{\mathrm{BLb}}, C_{\mathrm{BLb}, \text { eff }} \text { concentrations of pollutant in bulk and } \\
\text { effluent liquids }(\mathrm{M} \text { or } \mathrm{mg} / \mathrm{L}) \\
C_{\mathrm{BLb}, \mathrm{ss}} \\
\text { steady-state value of } C_{\mathrm{BLb}}(\mathrm{M} \text { or } \mathrm{mg} / \mathrm{L})\end{array}$ & $\begin{array}{l}\text { parameter of ozone, } \alpha_{\mathrm{AB}} k_{\mathrm{AB}} \mathrm{C}_{\mathrm{BLb} 0} \mathrm{D}_{\mathrm{A}} / k_{\mathrm{LA}}^{0^{2}} \\
\text { dimensionless ozonation reaction rate para- } \\
\text { meter of pollutant, } k_{\mathrm{AB}} C_{\mathrm{AGi} 0} D_{\mathrm{A}}^{2} /\left(H_{\mathrm{A}} k_{\mathrm{LA}}^{0^{2}} D_{\mathrm{B}}\right)\end{array}$ \\
\hline $\begin{array}{ll}C_{\text {BLb0 }} & \text { initial concentration of pollutant in bulk } \\
& \text { liquid }(\mathrm{M} \text { or } \mathrm{mg} / \mathrm{L})\end{array}$ & $\begin{array}{l}\text { dimensionless ozone self-decomposition reac- } \\
\text { tion rate parameter of oxygen, }\end{array}$ \\
\hline $\begin{array}{ll}C_{\mathrm{G}} & \text { total gas concentration in gas phase ( } \mathrm{M} \text { or } \\
\mathrm{mg} / \mathrm{L} \text { ) }\end{array}$ & $\begin{array}{l}\left(3 k_{\mathrm{d}} C_{\mathrm{AGi0}} H_{\mathrm{O}} D_{\mathrm{A}}^{2} /\left(2 C_{\mathrm{OGi} 0} H_{\mathrm{A}} k_{\mathrm{LA}}^{0^{2}} D_{\mathrm{O}}\right)\right) \\
\text { hydrostatic pressure as a function of location }\end{array}$ \\
\hline $\begin{array}{c}C_{\mathrm{OGi}}, C_{\mathrm{OGi} 0} \text { gas concentrations of oxygen of holdup } \\
\text { and inlet gases }(\mathrm{M} \text { or } \mathrm{mg} / \mathrm{L})\end{array}$ & $\begin{array}{ll} & \text { of column in Eq. }(12)(\mathrm{atm}) \\
P_{\mathrm{T}} & \text { gas pressure at free space }(\mathrm{atm})\end{array}$ \\
\hline $\begin{array}{c}C_{\mathrm{OLb}}, C_{\mathrm{OLb} \text {,eff }} \text { dissolved oxygen concentrations in } \\
\text { bulk and effluent liquids }(\mathrm{M} \text { or } \mathrm{mg} / \mathrm{L})\end{array}$ & $\begin{array}{c}P e_{\mathrm{G}}, P e_{\mathrm{L}} \text { Peclet numbers of gas and liquid phases, } \\
u_{\mathrm{G} 0} L /\left(E_{\mathrm{G}} \varepsilon_{\mathrm{G}}\right), u_{\mathrm{L}} L /\left(E_{\mathrm{L}} \varepsilon_{\mathrm{L}}\right)\end{array}$ \\
\hline 1 time $(\mathrm{M}$ or $\mathrm{mg} / \mathrm{L})$ & gas constant, $0.082 \mathrm{~atm} \mathrm{~L} / \mathrm{K} \mathrm{mol}$ \\
\hline $\begin{array}{l}\text { dissolved oxygen concentration in liquid film } \\
(\mathrm{M} \text { or } \mathrm{mg} / \mathrm{L})\end{array}$ & $\begin{array}{l}\text { retarding factor of oxygen mass transfer } \\
\text { defined by Eq. (10) }\end{array}$ \\
\hline $\begin{array}{l}\text { dissolved oxygen concentration of liquid film } \\
\text { at gas-liquid interface }(\mathrm{M} \text { or } \mathrm{mg} / \mathrm{L})\end{array}$ & $\begin{array}{ll}R_{\mathrm{uGL}} & \text { gas-liquid velocity ratio, } u_{\mathrm{G} 0} \varepsilon_{\mathrm{L}} /\left(u_{\mathrm{L}} \varepsilon_{\mathrm{G}}\right) \\
R_{\mathrm{LF}} & \text { ratio of modified volume of liquid to free }\end{array}$ \\
\hline $\begin{array}{ll}D_{\mathrm{A}}, D_{\mathrm{B}} \begin{array}{l}\text { molecular liquid diffusion coefficients of } \\
\text { ozone and pollutant }\left(\mathrm{m}^{2} / \mathrm{s}\right)\end{array}\end{array}$ & $\begin{array}{l}\text { space, } A \varepsilon_{\mathrm{L}} L u_{\mathrm{G} 0} /\left(V_{\mathrm{F}} u_{\mathrm{L}}\right) \\
S t_{\mathrm{GA}}, \quad S t_{\mathrm{GO}} \text { gas Stanton numbers of ozone and }\end{array}$ \\
\hline $\begin{array}{l}\text { molecular liquid diffusion coefficient of oxy- } \\
\text { gen }\left(\mathrm{m}^{2} / \mathrm{s}\right)\end{array}$ & $\begin{array}{c}\text { oxygen, } k_{\mathrm{LA}}^{0} a L /\left(u_{\mathrm{G} 0} H_{\mathrm{A}}\right), k_{\mathrm{LO}}^{0} a L /\left(u_{\mathrm{G} 0} H_{\mathrm{O}}\right) \\
S t_{\mathrm{LA}}, S t_{\mathrm{LO}} \text { liquid Stanton numbers of ozone and }\end{array}$ \\
\hline $\begin{array}{l}\text { Damköhler number of self-decomposition } \\
\text { reaction of ozone, } \varepsilon_{\mathrm{L}} k_{\mathrm{d}} L / u_{\mathrm{L}}\end{array}$ & $t \quad \begin{array}{l}\text { oxygen, } k_{\mathrm{LA}}^{0} a L / u_{\mathrm{L}}, k_{\mathrm{LO}}^{0} a L / u_{\mathrm{L}} \\
\text { time }(\mathrm{s})\end{array}$ \\
\hline $\begin{array}{l}\text { Damköhler number of pollutant ozonation } \\
\text { reaction of ozone, } \varepsilon_{\mathrm{L}} \alpha_{\mathrm{AB}} k_{\mathrm{AB}} L C_{\mathrm{BLb} 0} / u_{\mathrm{L}}\end{array}$ & $\begin{array}{l}\text { hydraulic retention time, } L \varepsilon_{\mathrm{L}} / u_{\mathrm{L}}(\min \text { or } \mathrm{s}) \\
\text { temperature }(\mathrm{K})\end{array}$ \\
\hline $\begin{array}{l}\text { Damköhler number of pollutant, } \\
\varepsilon_{\mathrm{L}} k_{\mathrm{AB}} L C_{\mathrm{AGi}} /\left(u_{\mathrm{L}} H_{\mathrm{A}}\right)\end{array}$ & $\begin{array}{l}\text { superficial gas velocity (up flow) }(\mathrm{m} / \mathrm{s} \text { or } \mathrm{cm} / \\
\mathrm{s})\end{array}$ \\
\hline Damköhler number of & inlet superficial gas velocity $(\mathrm{m} / \mathrm{s}$ or $\mathrm{cm} / \mathrm{s})$ \\
\hline $\begin{array}{cc}3 \varepsilon_{\mathrm{L}} k_{\mathrm{d}} L C_{\mathrm{AGi0}} H_{\mathrm{O}} /\left(2 u_{\mathrm{L}} C_{\mathrm{OGi} 0} H_{\mathrm{A}}\right) \\
\mathrm{DADM}\end{array}$ & $\begin{array}{l}\text { superficial liquid velocity (down flow) (m/s or } \\
\mathrm{cm} / \mathrm{s} \text { ) }\end{array}$ \\
\hline $\begin{array}{ll}E_{\mathrm{G}}, E_{\mathrm{L}} & \begin{array}{l}\text { axial dispersion coefficients of gas and liquid } \\
\left(\mathrm{m}^{2} / \mathrm{s}\right)\end{array}\end{array}$ & $\begin{array}{l}\text { dimensionless superficial gas velocity, } u_{\mathrm{G}} / u_{\mathrm{G} 0} \\
\text { volume of free space }\left(\mathrm{m}^{3}\right)\end{array}$ \\
\hline $\begin{array}{l}\text { enhancement factor of ozone mass transfer } \\
\text { defined by Eq. (9) }\end{array}$ & $\begin{array}{l}\text { distance from gas-liquid interface of liquid } \\
\text { film (m) }\end{array}$ \\
\hline average value of $E_{\mathrm{rA}}$ along the column & dimensionless form of $x, x / x_{M}$ \\
\hline unit conversion factor, $101,325 \mathrm{~Pa} / \mathrm{atm}$ & thickness of liquid film $(\mathrm{m}), D_{\mathrm{A}} / k_{\mathrm{LA}}^{0}$ \\
\hline $\begin{array}{l}\text { standard acceleration of gravity, } 9.8 \mathrm{~m} / \mathrm{s}^{2} \\
\text { height of rising gas bubbles at time } t(\mathrm{~m})\end{array}$ & $\begin{array}{l}\text { mole fractions of ozone and oxygen of inlet } \\
\text { gas }\end{array}$ \\
\hline dimensionless form of $h_{\mathrm{B}}, h_{\mathrm{B}} / L$ & axial coordinate of column from bottom (m) \\
\hline
\end{tabular}




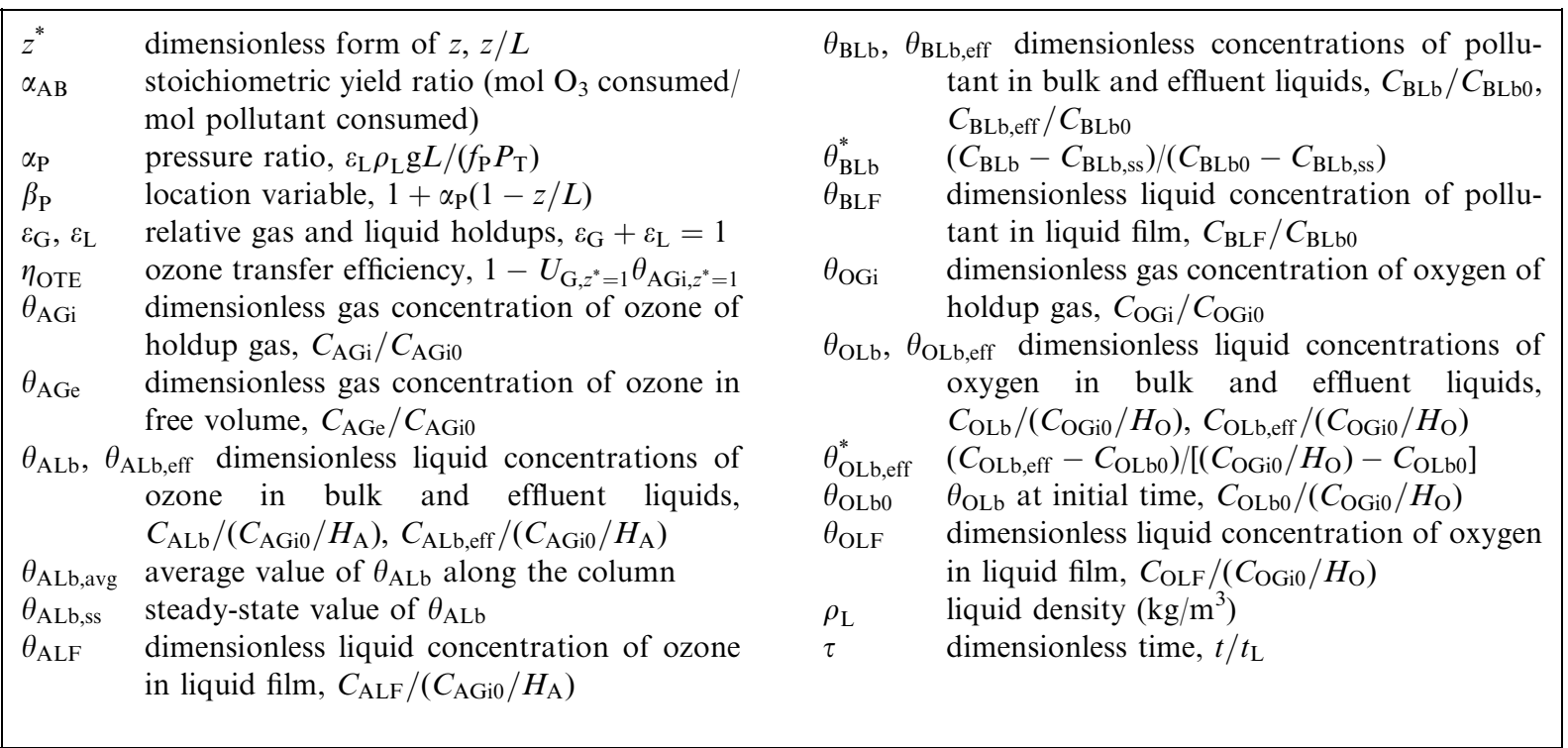

into pure oxygen or oxygen-enriched gas through an ozone generator. The mixture of gases composed of oxygen and ozone is then transferred to water by bubbling it through the bulk solution. The efficiency of ozonation with pollutants is usually based on the residual concentrations of ozone and pollutant. It is clear that quantification of the concentration variation of ozone and pollutant is critical to the rational design and optimization operation of ozonation system.

Bubble column reactors (BCRs) have commonly been used in plants and laboratories for ozone contacting in the United States and throughout the world. When compared with other ozone contactors, BCRs offer the advantages of no moving parts, high liquid-phase content for treatment, reasonable mass transfer rates under low energy input, little required space, and relatively low cost [1]. The ozone-containing gas is introduced into the bottom of the column, while the direction of liquid flow may be cocurrent or countercurrent. According to the previous studies of Chen et al. [2] and Zhou et al. [3], a countercurrent bubble column has the higher ozone transfer efficiency than a cocurrent one. Thus, the investigation of this paper is aimed at the countercurrent bubble column. Because the gaseous ozone is not completely transferred into the water, the columns are covered to hold the off-gas containing the residual ozone. The off-gas of high-purity oxygen from the headspace of the bubble column can be recycled to the ozone generator. Otherwise the residual ozone must be removed by a destruction process before the gas is discharged. Therefore, the information of residual ozone concentration and amount of the off-gas are valuable for the follow-up treatment of being recycled or discharged.
Certainly, there exists a temporary and unsteady period before the ozonation system in BCRs reaches steady state. Available ozonation models employed for the description of ozone and pollutant concentration profiles have commonly been developed for steady state [4-6]. Such information about the dynamic processes of ozonation with pollutants is still scarce. Accordingly, treating qualities of water, such as the degree of pollutant removal in the early stage of ozonation, are usually not predicted, and the time required for the steady-state establishment remains to be determined. Furthermore, one of the advantages of ozonation is that it contributes dissolved oxygen because oxygen may be used in the biological process after the residual ozone has been decomposed. Ozone concentration is usually relatively low in the carrier gas containing the majority of the oxygen. However, the oxygen mass transfer has usually been neglected in previous ozonation models. This is because the solubility of oxygen is quite a bit lower than that of ozone. Oxygen is, thus, usually taken as an inert gas for the ozone-oxygen mixture. Therefore, there is a lack of information about the increase of dissolved oxygen concentration in the ozonation process.

Referring to our previous studies of the dynamic ozone dissolution and disinfection models [2,7], the contribution of this study is to model and investigate the dynamic processes of ozonation with pollutant in a countercurrent bubble column with oxygen mass transfer. Three major factors were considered for the dynamic ozonation model: (1) the system hydrodynamic behavior, (2) the gas-liquid mass transfer, and (3) the ozonation reaction kinetics. The dynamic axial dispersion model (DADM) proposed in this paper considers these three major factors simultaneously. Based on the 
DADM, the dynamic variations of the ozone, pollutant, and oxygen concentration profiles can be predicted. Further, the experimental data of the $o$-cresol ozonation in the pilot-scale tests were obtained for the model verification. The $o$-cresol is one of the main phenolic pollutants in wastewater and was chosen as the model pollutant. As a result, the validity of the model was demonstrated by the good agreement of the predicted results with the experimental data. Consequently, the model proposed can provide useful information about the dynamic behavior of ozonation with pollutant in a countercurrent bubble column.

\section{Theoretical analysis}

\subsection{Ozonation kinetics and film model}

For modeling the dynamic behavior of ozonation with pollutants in a countercurrent bubble column, it is necessary to quantify the rates of mass transfer and chemical reactions associated with the hydrodynamic condition of the contactor. The mass transfer of ozone (denoted as A) and oxygen (denoted as O) from the gas to liquid phase can be described by the two-film model [8]. As the ozone is dissolved in water, it may be consumed via the self-decomposition $\left(2 \mathrm{O}_{3} \rightarrow 3 \mathrm{O}_{2}\right)$ and oxidation with the pollutant (denoted as B). Regarding the spontaneous ozone decomposition and reaction with the pollutant, this study proposes the following pseudofirst-order and second-order reaction rate expressions, respectively [9]:

$\mathrm{d} C_{\mathrm{ALb}} / \mathrm{d} t=-k_{\mathrm{d}} C_{\mathrm{ALb}}-\alpha_{\mathrm{AB}} k_{\mathrm{AB}} C_{\mathrm{ALb}} C_{\mathrm{BLb}}$,

$\mathrm{d} C_{\mathrm{BLb}} / \mathrm{d} t=-k_{\mathrm{AB}} C_{\mathrm{ALb}} C_{\mathrm{BLb}}$,

$\mathrm{d} C_{\mathrm{OLb}} / \mathrm{d} t=3 k_{\mathrm{d}} C_{\mathrm{ALb}} / 2$.

With the ozone consumption and oxygen formation, the mass transfer rates of ozone and oxygen may be enhanced and retarded, respectively [7]. The ratios of the mass transfer rates of ozone and oxygen with the ozone consumption and the oxygen formation to those without may be designated by the enhancement factor of ozone consumption $\left(E_{\mathrm{rA}}\right)$ and the retarding factor of oxygen formation $\left(R_{\mathrm{fO}}\right)$, respectively. According to the film model, the $E_{\mathrm{rA}}$ and $R_{\mathrm{fO}}$ of ozone and oxygen, respectively, can be calculated according to Eqs. (4)(10) in dimensionless forms. Note that the resistance of the gas-liquid mass transfer is mainly contributed by the liquid phase for the ozone contacting process [2]. Also, the concentrations of ozone and oxygen in the liquid film at gas-liquid interface $(x=0)$ are in equilibrium with those in the gas phase, respectively. Furthermore, the volatility of pollutant can be usually neglected. Thus, the concentration gradient of pollutant $\left(\mathrm{d} C_{\mathrm{BLb}} / \mathrm{d} x\right)$ in the liquid film at $x=0$ can be taken as zero. At the boundary between the liquid film and the bulk liquid $\left(x=x_{\mathrm{M}}\right)$, the concentrations of ozone, oxygen, and pollutant in the liquid film are equal to those in the bulk liquid, respectively. The system equations, boundary conditions, and $E_{\mathrm{rA}}$ and $R_{\mathrm{fO}}$ of the liquid film are then expressed by Eqs. (4)-(6), Eqs. (7) and (8), and Eqs. (9) and (10), respectively, as follows:

Equations in the liquid film:

$$
\begin{aligned}
& d^{2} \theta_{\mathrm{ALF}} / \mathrm{d} x^{* 2}=M_{\mathrm{A}} \theta_{\mathrm{ALF}}+M_{\mathrm{AB}} \theta_{\mathrm{ALF}} \theta_{\mathrm{BLF}}, \\
& d^{2} \theta_{\mathrm{BLF}} / \mathrm{d} x^{* 2}=M_{\mathrm{B}} \theta_{\mathrm{ALF}} \theta_{\mathrm{BLF}}, \\
& d^{2} \theta_{\mathrm{OLF}} / \mathrm{d} x^{* 2}=-M_{\mathrm{O}} \theta_{\mathrm{ALF}} .
\end{aligned}
$$

Boundary conditions:

$$
\begin{aligned}
& x^{*}=0, \quad \theta_{\mathrm{ALF}}=\theta_{\mathrm{AGi}}, \quad \mathrm{d} \theta_{\mathrm{BLF}} / \mathrm{d} x^{*}=0, \\
& \theta_{\mathrm{OLF}}=\theta_{\mathrm{OGi}}, \\
& x^{*}=1, \quad \theta_{\mathrm{ALF}}=\theta_{\mathrm{ALb}}, \quad \theta_{\mathrm{BLF}}=\theta_{\mathrm{BLb}}, \quad \theta_{\mathrm{OLF}}=\theta_{\mathrm{OLb}}
\end{aligned}
$$

Equations for $E_{\mathrm{rA}}$ and $R_{\mathrm{fO}}$ :

$E_{\mathrm{rA}}=-\left.\left(\mathrm{d} \theta_{\mathrm{ALF}} / \mathrm{d} x^{*}\right)\right|_{x^{*}=0} /\left(\theta_{\mathrm{AGi}}-\theta_{\mathrm{ALb}}\right)$,
$R_{\mathrm{fO}}=-\left.\left(\mathrm{d} \theta_{\mathrm{OLF}} / \mathrm{d} x^{*}\right)\right|_{x^{*}=0} /\left(\theta_{\mathrm{OGi}}-\theta_{\mathrm{OLb}}\right)$.

\subsection{Dynamic axial dispersion model}

The hydrodynamic condition of the contactor affects the concentration profiles. A dynamic axial dispersion model is developed to describe the dynamic variation of concentration profiles of ozonation with pollutant in a bubble column. Assumptions of the model are as follows $[3,10]$ :

1. The homogeneous bubbling flow regime holds. The dispersion coefficients, gas holdup, and mass transfer coefficients are constant along the height of column.

2. The end effect of the column is neglected.

3. Pressure varies linearly with the column height owing to the hydrostatic head.

4. Henry's law applies.

5. Reactions in the gas phase are neglected.

The axial dispersion model has been commonly used and found valid for the flow conditions in almost all types of BCRs [11]. However, the assumption of the homogeneous bubbling flow regime is tenable for smaller gas velocity $\left(u_{\mathrm{G} 0}<3 \mathrm{~cm} / \mathrm{s}\right)$ as explained by Deckwer [12]. A review of the previous studies on ozone contacting processes, such as those of Mariñas et al. [10] and Chen et al. [7], with $u_{\mathrm{G} 0}=0.05$ and $0.133-0.948 \mathrm{~cm} /$ $\mathrm{s}$, respectively, indicated that the operating conditions of the gas velocity are in the homogeneous bubbling flow 
regime. Based on the above assumptions, the overall mass balance of gas phase may be described by

$$
\begin{aligned}
\varepsilon_{\mathrm{G}} \frac{\partial C_{\mathrm{G}}}{\partial t}= & \varepsilon_{\mathrm{G}} E_{\mathrm{G}} \frac{\partial^{2} C_{\mathrm{G}}}{\partial z^{2}}-\frac{\partial\left(u_{\mathrm{G}} C_{\mathrm{G}}\right)}{\partial z} \\
& -E_{\mathrm{rA}} k_{\mathrm{LA}}^{0} a\left(\frac{C_{\mathrm{AGi}}}{H_{\mathrm{A}}}-C_{\mathrm{ALb}}\right) \\
& -R_{\mathrm{fO}} k_{\mathrm{LO}}^{0} a\left(\frac{C_{\mathrm{OGi}}}{H_{\mathrm{O}}}-C_{\mathrm{OLb}}\right) .
\end{aligned}
$$

In Eq. (11), the left-hand side term represents the variation of the local gas concentration, while the right-hand side terms stand for the dispersion effect, convection, and ozone and oxygen mass transfers, respectively.

Applying the ideal gas equation and noticing that the hydrostatic pressure $(P)$ decreases linearly with the axial coordinate $(z)$ from the bottom of column, one has

$C_{\mathrm{G}}=\frac{P}{R T}=\frac{P_{\mathrm{T}}+\varepsilon_{\mathrm{L}} \rho_{\mathrm{L}} g(L-z)}{R T}=\frac{P_{\mathrm{T}} \beta_{\mathrm{P}}}{R T}$

with $\beta_{\mathrm{P}}=1+\alpha_{\mathrm{P}}(1-z / L)$, and $\alpha_{\mathrm{P}}=\varepsilon_{\mathrm{L}} \rho_{\mathrm{L}} g L /\left(f_{\mathrm{P}} P_{\mathrm{T}}\right)$.

The relative gas $\left(\varepsilon_{\mathrm{G}}\right)$ and liquid $\left(\varepsilon_{\mathrm{L}}\right)$ holdups, with the relationship of $\varepsilon_{\mathrm{G}}+\varepsilon_{\mathrm{L}}=1$, represent the volume proportions of holdup gas and bulk liquid in the bubble column, respectively. Substituting Eq. (12) into Eq. (11) and putting it in the dimensionless form, one may obtain Eq. (13) for the dimensionless superficial gas velocity ( $U_{\mathrm{G}}$, with $U_{\mathrm{G}}=u_{\mathrm{G}} / u_{\mathrm{G} 0}$ ). As shown in Eq. (12), $C_{\mathrm{G}}$ is a linear function of $z$. Therefore, the time differential and the axial coordinate quadratic differential terms of $C_{\mathrm{G}}$ in Eq. (11) would be eliminated after $C_{\mathrm{G}}$ is transformed by Eq. (12). Furthermore, it should be noted that the applicable region of Eq. (13) is restricted from the bottom of column to the height of rising gas bubbles $\left(h_{\mathrm{B}}\right)$. The value of $h_{\mathrm{B}}$ initially increases with the ozonation time, and then reaches a constant height of $L$. The equation of $U_{\mathrm{G}}$ and the corresponding boundary conditions are as follows:

$$
\begin{aligned}
\frac{\mathrm{d} U_{\mathrm{G}}}{\mathrm{d} z^{*}}= & \frac{\alpha_{\mathrm{P}}}{\beta_{\mathrm{P}}} U_{\mathrm{G}}-E_{\mathrm{rA}} S t_{\mathrm{GA}} \frac{1+\alpha_{\mathrm{P}}}{\beta_{\mathrm{P}}} y_{\mathrm{A}}\left(\theta_{\mathrm{AGi}}-\theta_{\mathrm{ALb}}\right) \\
& -R_{\mathrm{fO}} S t_{\mathrm{GO}} \frac{1+\alpha_{\mathrm{P}}}{\beta_{\mathrm{P}}} y_{\mathrm{O}}\left(\theta_{\mathrm{OGi}}-\theta_{\mathrm{OLb}}\right)
\end{aligned}
$$

for $0 \leqslant z^{*} \leqslant h_{\mathrm{B}}^{*}$, with the boundary condition (BC)

$z^{*}=0, \quad U_{G}=1$

for $h_{\mathrm{B}}^{*}<z^{*} \leqslant 1, U_{\mathrm{G}}=0$. The dimensionless height of gas bubbles $\left(h_{\mathrm{B}}^{*}\right.$, with $\left.h_{\mathrm{B}}^{*}=h_{\mathrm{B}} / L\right)$ at time $\tau\left(=t / t_{\mathrm{L}}\right)$, which can be calculated by Eq. (15), has a maximum value of unit.

$\frac{\mathrm{d} h_{\mathrm{B}}^{*}}{\mathrm{~d} \tau}=R_{\mathrm{uGL}} U_{G, z^{*}=h_{\mathrm{B}}^{*}}$

with the initial condition (IC)

$\tau=0, \quad h_{\mathrm{B}}^{*}=0$.
Further, the dimensionless governing equations of gas ozone $\left(\theta_{\mathrm{AGi}}\right.$, with $\left.\theta_{\mathrm{AGi}}=C_{\mathrm{AGi}} / C_{\mathrm{AGi} 0}\right)$ and oxygen $\left(\theta_{\mathrm{OGi}}\right.$, with $\left.\theta_{\mathrm{OGi}}=C_{\mathrm{OGi}} / C_{\mathrm{OGi} 0}\right)$ are expressed by

$$
\begin{aligned}
\frac{\partial \theta_{\mathrm{AGi}}}{\partial \tau}= & R_{\mathrm{uGL}}\left[\frac{1}{P e_{\mathrm{G}}} \frac{\partial^{2} \theta_{\mathrm{AGi}}}{\partial z^{* 2}}-\frac{\partial\left(U_{\mathrm{G}} \theta_{\mathrm{AGi}}\right)}{\partial z^{*}}\right. \\
& \left.-E_{\mathrm{rA}} S t_{\mathrm{GA}}\left(\theta_{\mathrm{AGi}}-\theta_{\mathrm{ALb}}\right)\right], \\
\frac{\partial \theta_{\mathrm{OGi}}}{\partial \tau}= & R_{\mathrm{uGL}}\left[\frac{1}{P e_{\mathrm{G}}} \frac{\partial^{2} \theta_{\mathrm{OGi}}}{\partial z^{* 2}}-\frac{\partial\left(U_{\mathrm{G}} \theta_{\mathrm{OGi}}\right)}{\partial z^{*}}\right. \\
& \left.-R_{\mathrm{fO}} S t_{\mathrm{GO}}\left(\theta_{\mathrm{OGi}}-\theta_{\mathrm{OLb}}\right)\right] .
\end{aligned}
$$

The dimensionless liquid phase governing equations for ozone $\left(\theta_{\mathrm{ALb}}\right.$ with $\left.\theta_{\mathrm{ALb}}=C_{\mathrm{ALb}} /\left(C_{\mathrm{AGi} 0} / H_{\mathrm{A}}\right)\right)$, pollutant $\left(\theta_{\mathrm{BLb}}\right.$ with $\left.\theta_{\mathrm{BLb}}=C_{\mathrm{BLb}} / C_{\mathrm{BLb} 0}\right)$ and oxygen $\left(\theta_{\mathrm{OLb}}\right.$ with $\left.\theta_{\mathrm{OLb}}=C_{\mathrm{OLb}} /\left(C_{\mathrm{OGi} 0} / H_{\mathrm{O}}\right)\right)$ should consider the chemical reaction terms according to Eqs. (1)-(3) and are as follows:

$$
\begin{aligned}
\frac{\partial \theta_{\mathrm{ALb}}}{\partial \tau}= & \frac{1}{P e_{\mathrm{L}}} \frac{\partial^{2} \theta_{\mathrm{ALb}}}{\partial z^{* 2}}+\frac{\partial \theta_{\mathrm{ALb}}}{\partial z^{*}} \\
& +E_{\mathrm{rA}} S t_{\mathrm{LA}}\left(\theta_{\mathrm{AGi}}-\theta_{\mathrm{ALb}}\right) \\
& -D a_{\mathrm{A}} \theta_{\mathrm{ALb}}-D a_{\mathrm{AB}} \theta_{\mathrm{ALb}} \theta_{\mathrm{BLb}}, \\
\frac{\partial \theta_{\mathrm{BLb}}}{\partial \tau}= & \frac{1}{P e_{\mathrm{L}}} \frac{\partial^{2} \theta_{\mathrm{BLb}}}{\partial z^{* 2}}+\frac{\partial \theta_{\mathrm{BLb}}}{\partial z^{*}}-D a_{\mathrm{B}} \theta_{\mathrm{ALb}} \theta_{\mathrm{BLb}}, \\
\frac{\partial \theta_{\mathrm{OLb}}}{\partial \tau}= & \frac{1}{P e_{\mathrm{L}}} \frac{\partial^{2} \theta_{\mathrm{OLb}}}{\partial z^{* 2}}+\frac{\partial \theta_{\mathrm{OLb}}}{\partial z^{*}} \\
& +R_{\mathrm{fO}} S t_{\mathrm{LO}}\left(\theta_{\mathrm{OGi}}-\theta_{\mathrm{OLb}}\right)+D a_{\mathrm{O}} \theta_{\mathrm{ALb}},
\end{aligned}
$$

The dimensionless governing equation of off-gas ozone $\left(\theta_{\mathrm{AGe}}\right.$ with $\left.\theta_{\mathrm{AGe}}=C_{\mathrm{AGe}} /\left(C_{\mathrm{AGi} 0} / H_{\mathrm{A}}\right)\right)$ in the free space can be expressed as follows:

$\frac{\mathrm{d} \theta_{\mathrm{AGe}}}{\mathrm{d} \tau}=R_{\mathrm{LF}} U_{\mathrm{G}, z^{*}=1}\left(\theta_{\mathrm{AGi}, z^{*}=1}-\theta_{\mathrm{AGe}}\right)$.

The ICs of Eqs. (17)-(22) are

$\tau=0, \quad \theta_{\mathrm{AGi}}=\theta_{\mathrm{OGi}}=\theta_{\mathrm{ALb}}=\theta_{\mathrm{AGe}}=0$,

$\theta_{\mathrm{BLb}}=1, \quad \theta_{\mathrm{OLb}}=\theta_{\mathrm{OLb} 0}$.

The applicable BCs of Eqs. (17)-(21) are as follows:At the bottom, $z^{*}=0$ :

$$
\begin{aligned}
& \theta_{\mathrm{AGi}}=1+\frac{1}{P e_{\mathrm{G}}} \frac{\partial \theta_{\mathrm{AGi}}}{\partial z^{*}} \theta_{\mathrm{OGi}}=1+\frac{1}{P e_{\mathrm{G}}} \frac{\partial \theta_{\mathrm{OGi}}}{\partial z^{*}}, \\
& \frac{\partial \theta_{\mathrm{ALb}}}{\partial z^{*}}=\frac{\partial \theta_{\mathrm{BLb}}}{\partial z^{*}}=\frac{\partial \theta_{\mathrm{OLb}}}{\partial z^{*}}=0 . \\
& \mathrm{At} z^{*}=h_{\mathrm{B}}^{*}: \\
& \frac{\partial \theta_{\mathrm{AGi}}}{\partial z^{*}}=0, \quad \frac{\partial \theta_{\mathrm{OGi}}}{\partial z^{*}}=0, \\
& \theta_{\mathrm{ALb}}=-\frac{1}{P e_{\mathrm{L}} \partial \theta_{\mathrm{ALb}}}, \quad \theta_{\mathrm{BLb}}=1-\frac{1}{P e_{\mathrm{L}}} \frac{\partial \theta_{\mathrm{BLb}}}{\partial z^{*}}, \\
& \theta_{\mathrm{OLb}}=\theta_{\mathrm{OLb} 0}-\frac{1}{P e_{\mathrm{L}}} \frac{\partial \theta_{\mathrm{OLb}}}{\partial z^{*}} .
\end{aligned}
$$


In the above equations, the definitions of the dimensionless variables and parameter groups are listed in the nomenclature. Note that the Peclet numbers represent the flow conditions. As the values of the Peclet numbers become large, the system tends to approach plug flow. For small values of the Peclet numbers, the flow condition behaves like complete mixing. Furthermore, the Stanton and Damköhler numbers stand for the significance of gas-liquid mass transfer and chemical reactions, respectively.

\subsection{Computation algorithm for solving the mode}

Eqs. (4)-(10) and (13)-(27) represent the governing equations of DADM for predicting the dynamic and axial variations of ozone, pollutant and oxygen concentration profiles in a bubble column. The present work considers: (1) the dynamic state, (2) the oxygen mass transfer, (3) the chemical reactions of self-decomposition of ozone and of ozonation of pollutant with ozone, (4) the effect of chemical reactions on mass transfer, and (5) the superficial gas velocity variation. The finite difference method based on the Taylor series is employed with the Turbo $\mathrm{C}$ program in this study. Eqs. (4)-(8) are firstly solved using the iterative method to obtain the values of $\theta_{\mathrm{ALF}}, \theta_{\mathrm{BLF}}$, and $\theta_{\mathrm{OLF}}$ in the film, yielding the values of $E_{\mathrm{rA}}$ and $R_{\mathrm{fO}}$ from Eqs. (9) and (10) at time $\tau$. The obtained $E_{\mathrm{rA}}$ and $R_{\mathrm{fO}}$ are substituted into Eq. (13) along with Eq. (14) to compute $U_{\mathrm{G}}$. Eqs. (15)-(27) are then solved using the forward-difference method to compute the values of the variables in the next time step of $\tau+\Delta \tau$ from the available values at $\tau$. This is followed by the computation of $E_{\mathrm{rA}}, R_{\mathrm{fO}}$, and $U_{\mathrm{G}}$ at $\tau+\Delta \tau$. The computation is conducted up to the steady state. The grids along $x^{*}$ or $z^{*}=0$ to 1 and the size of the time step $(\Delta \tau)$ adopted in the program are 101 points and $10^{-5}$, respectively. The confidential error range of the numerical mass balance check for the numerical scheme used is less than $10^{-6}$. The present model consisted of several partial differential equations is difficult to obtain the analytic solution, if it is not impossible. For the verification of the numerical methods employed, the present model is properly simplified to simulate the ozone contacting processes of Mariñas et al. [10] and Zhou et al. [3], which plotted the steady-state gas and dissolved ozone concentration profiles in the bubble column. The comparison shows the good agreements. Thus, the numerical model and solution of this study should be reliable.

\section{Experimental}

\subsection{Chemicals}

The $\mathrm{pH}$ adjustment of experimental solution is controlled at 2.0 by adding phosphoric acid/sodium hydroxide buffers in deionized water with the total phosphate concentration of $0.01 \mathrm{M}$ [13]. The corresponding ionic strength of solution is about $0.02 \mathrm{M}$. The $o$-cresol with the chemical formula as $\mathrm{CH}_{3} \mathrm{C}_{6} \mathrm{H}_{4} \mathrm{OH}$, which is purchased in reagent grade from Hayashi Pure Chemical (Osaka, Japan) and used without further purification, has the molecular weight of 108.14. The initial concentration of $o$-cresol $\left(C_{\mathrm{BLb} 0}\right)$ used in the experiments is $10^{-3} \mathrm{M}$, which is high relative to that of ozone so as to ensure that ozone is consumed mainly by the reaction with $o$-cresol [14].

\subsection{Instrumentation}

The experimental apparatus employed in this work is shown in Fig. 1. Ozone-containing gas generated by pure oxygen $\left(y_{\mathrm{A}}+y_{\mathrm{O}}=1\right)$ is introduced into the column with $u_{\mathrm{G} 0}=1.33$ and $7.40 \mathrm{~mm} / \mathrm{s}$. The flow condition of ozonation system is countercurrent with continuous gas and liquid streams. The liquid-storage tank is equipped with the thermostat to maintain a constant temperature of solution at $21^{\circ} \mathrm{C}$ in all experiments. A solution of about $1.33 \mathrm{~m}$ height $(L)$ is held in the column, while the aspect ratio of the height to diameter is 8.42 . The superficial velocity of liquid $\left(u_{\mathrm{L}}\right)$ is at $4.25 \mathrm{~mm} / \mathrm{s}$. The meter of dissolved oxygen (model Oxi 340, Wissenschaftlich-Technische Werkstätten GmbH \& Co. KG (WTW), Weilheim, Germany) with the sensor of model CellOx 325 (WTW, Weilheim, Germany) is used to measure the dissolved oxygen concentration $\left(C_{\mathrm{OLb}}\right)$ continuously. The liquid dissolved ozone concentration $\left(C_{\mathrm{ALb}}\right)$ is analyzed by the indigo method. The $o$-cresol concentration $\left(C_{\mathrm{BLb}}\right)$ is analyzed using high performance liquid chromatography (HPLC) system with $250 \times 4.6 \mathrm{~mm}$ model $516 \mathrm{C} 18(5 \mu \mathrm{m})$ column (SUPELCO, Bellefonte, PA, USA), and UV/visible detector (model 1706, Bio-Rad, Hercules, CA, USA) at $271 \mathrm{~nm}$. The HPLC effluent with flow rate of $1.0 \mathrm{~mL} /$ min has the composition with water: $\mathrm{CH}_{3} \mathrm{CN}$ of 74:26. The injection volume of analytic solution is $20 \mu \mathrm{L}$. The gas holdup $\left(\varepsilon_{\mathrm{G}}\right)$ is estimated by the differential hydrostatic pressure method. The detailed geometric size and operation conditions of the BCR may be found elsewhere [7].

\subsection{Experimental procedures}

Before starting the ozonation experiments, the ozonecontaining gas is bypassed to the photometric analyzer (model SOZ-6004, Seki, Tokyo, Japan) to assure the stability and determine the inlet ozone concentration $\left(C_{\mathrm{AGi0}}\right)$. The mole fractions of feed ozone $\left(y_{\mathrm{A}}\right)$ are 0.0172 and 0.0143 for $u_{\mathrm{G} 0}=7.40$ and $1.33 \mathrm{~mm} / \mathrm{s}$, respectively. The initial dissolved oxygen concentration $\left(C_{\mathrm{OLb} 0}\right)$ is measured prior to the introduction of gas while water flows continuously with other conditions maintained at 


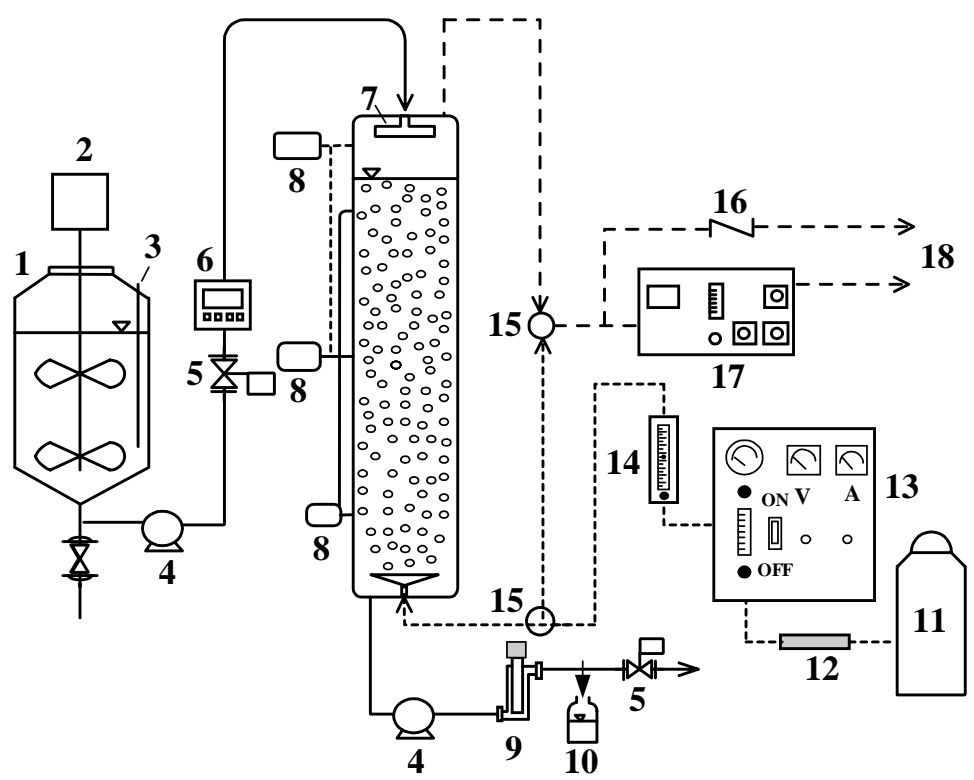

Fig. 1. Experimental apparatus sketch. Components: (1) liquid-storage tank, (2) stirrer, (3) thermostat, (4) pumps, (5) control valves, (6) liquid flow meter, (7) liquid sparger, (8) pressure transmitters, (9) dissolved oxygen sensor, (10) sampling port, (11) oxygen cylinder, (12) drying tube, (13) ozone generator, (14) gas flow meter, (15) three-way valves, (16) check valve, (17) gaseous ozone detector, and (18) vent to hood.

the set values. The gas stream at the preset flow rate $\left(u_{\mathrm{G} 0}\right)$ is directed into the column at initial time $(t=0)$. The variations of effluent dissolved oxygen concentration $\left(C_{\mathrm{OLb}, \text { eff }}\right)$ are monitored and analyzed to obtain the values of oxygen mass transfer coefficient $\left(k_{\mathrm{LO}}^{0} a\right)$. The ozonation experiments of $o$-cresol are carried out for about five hydraulic retention times to approach the steady state. The effluent liquid is sampled at desired intervals to analyze the variations of $C_{\mathrm{BLb}}$ and $C_{\mathrm{ALb}}$ in the course of experiments. In addition, the ozone concentration and amount of the off-gas are also measured.

\subsection{Values of parameters for modeling}

The values of some parameters for modeling are determined according to the results of previous studies. Values of $D_{\mathrm{B}}, H_{\mathrm{A}}$ and $\alpha_{\mathrm{AB}}$ were reported as $1.05 \times 10^{-9} \mathrm{~m}^{2} / \mathrm{s}, 4.1$ and 2 , respectively [14]. The reaction rate constants $k_{\mathrm{AB}}$ and $k_{\mathrm{d}}$ of $12,000 \mathrm{M}^{-1} \mathrm{~s}^{-1}$ and $0.00024 \mathrm{~s}^{-1}$ were obtained from Hoigné and Bader [13] and Sotelo et al. [15], respectively. The values of $k_{\mathrm{LA}}^{0}$ can be calculated as $1.95 \times 10^{-4}$ and $2.11 \times 10^{-4} \mathrm{~m} / \mathrm{s}$ for $u_{\mathrm{G} 0}=7.40$ and $1.33 \mathrm{~mm} / \mathrm{s}$, respectively, from the Eqs. (6) to (8) of Mariñas et al. [10]. Then, the values of $k_{\mathrm{LO}}^{0}$ can be corrected from $k_{\mathrm{LA}}^{0}$ as $2.20 \times 10^{-4}$ and $2.38 \times 10^{-4} \mathrm{~m} / \mathrm{s}$ for $u_{\mathrm{G} 0}=7.40$ and $1.33 \mathrm{~mm} / \mathrm{s}$, respectively, according to the surface renewal theory. Other modeling parameters except the gas-liquid interfacial area (a) and gas holdup $\left(\varepsilon_{\mathrm{G}}\right)$, were obtained employing the results of Chen et al. [7] as follows: $D_{\mathrm{A}}=1.76 \times 10^{-9} \mathrm{~m}^{2} / \mathrm{s} ; \quad D_{\mathrm{O}}=2.24 \times 10^{-9} \mathrm{~m}^{2} / \mathrm{s} ; \quad E_{\mathrm{L}}=$ 0.03261 and $0.00852 \mathrm{~m}^{2} / \mathrm{s}$ at $u_{\mathrm{G} 0}=7.40$ and $1.33 \mathrm{~mm} / \mathrm{s}$, respectively; $H_{\mathrm{O}}=30.81$; and $P e_{\mathrm{G}}=500$.

\section{Results and discussion}

\subsection{Ozonation of o-cresol and model verification}

The temporal concentration variations of residual $o$ cresol and dissolved oxygen in the effluent liquid, and off-gas ozone in the free volume are measured and compared with the prediction. In addition, the dissolved ozone concentration, the enhancement factor of ozone, the retardation factor of oxygen, and the amount of offgas are predicted simultaneously. The gas holdup $\left(\varepsilon_{\mathrm{G}}\right)$ values of 0.0445 and 0.0113 are estimated from the experiments for $u_{\mathrm{G} 0}=7.40$ and $1.33 \mathrm{~mm} / \mathrm{s}$, respectively. The curves of the concentration of dissolved oxygen in the effluent liquid $\left(\theta_{\mathrm{OLb}, \mathrm{eff}}^{*}\right)$ can be well predicted based on the DADM with the proper values of the gas-liquid interfacial area (a) as shown in Fig. 2. The values of a for $u_{\mathrm{G} 0}=7.40$ and $1.33 \mathrm{~mm} / \mathrm{s}$ are determined as 341 and $95 \mathrm{~m}^{-1}$, respectively. Accordingly, the values of $k_{\mathrm{LO}}^{0} a$ of this study (0.075 and $0.023 \mathrm{~s}^{-1}$ with $a=341$ and $95 \mathrm{~m}^{-1}$, and $k_{\mathrm{LO}}^{0}=2.20 \times 10^{-4}$ and $2.38 \times 10^{-4} \mathrm{~m} / \mathrm{s}$, respectively) are greater than those $\left(k_{\mathrm{LO}}^{0} a=0.017\right.$ and $0.007 \mathrm{~s}^{-1}$ with $\varepsilon_{\mathrm{G}}=0.0285$ and 0.0044 , respectively) obtained from the oxygen aeration in the deionized 


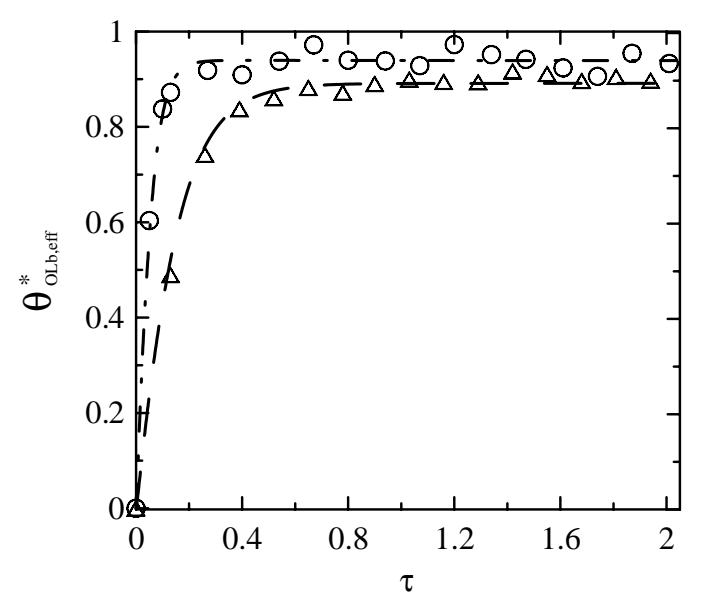

Fig. 2. Concentration variations of $\theta_{\mathrm{OLb} \text {,eff }}^{*}$ with $\tau$ for $o$-cresol ozonation in countercurrent bubble column. Symbols, lines: experiments, prediction. $\bigcirc$ and - - $\triangle$ and - $u_{\mathrm{G} 0}=7.40 \mathrm{~mm} / \mathrm{s} \quad\left(D a_{\mathrm{A}}=0.072, \quad D a_{\mathrm{AB}}=7177, \quad D a_{\mathrm{B}}=699.6\right.$, $D a_{\mathrm{O}}=0.014, \quad M_{\mathrm{A}}=1.11 \times 10^{-5}, \quad M_{\mathrm{AB}}=1.11, \quad M_{\mathrm{B}}=0.181$, $M_{\mathrm{O}}=1.71 \times 10^{-6}, \quad P e_{\mathrm{G}}=500, \quad P e_{\mathrm{L}}=0.181, \quad R_{\mathrm{LF}}=20.7$, $R_{\mathrm{uGL}}=37.4, S t_{\mathrm{GA}}=2.92, S t_{\mathrm{GO}}=0.439, S t_{\mathrm{LA}}=20.9, S t_{\mathrm{LO}}=$ $\left.23.6, \quad \alpha_{\mathrm{P}}=0.123\right), \quad 1.33 \mathrm{~mm} / \mathrm{s} \quad\left(D a_{\mathrm{A}}=0.074, \quad D a_{\mathrm{AB}}=7426\right.$, $D a_{\mathrm{B}}=603.2, D a_{\mathrm{O}}=0.012, M_{\mathrm{A}}=9.46 \times 10^{-6}, M_{\mathrm{AB}}=0.946$, $M_{\mathrm{B}}=0.129, \quad M_{\mathrm{O}}=1.21 \times 10^{-6}, \quad P e_{\mathrm{G}}=500, \quad P e_{\mathrm{L}}=0.671$, $R_{\mathrm{LF}}=3.84, R_{\mathrm{uGL}}=27.3, S t_{\mathrm{GA}}=4.88, S t_{\mathrm{GO}}=0.733, S t_{\mathrm{LA}}=$ $\left.6.26, S t_{\mathrm{LO}}=7.07, \alpha_{\mathrm{P}}=0.127\right) ; R^{2}=0.993,0.996$.

water of Chen et al. [7]. One may regard that the higher values of $k_{\mathrm{LO}}^{0} a$ of this work are attributed to the higher values of $\varepsilon_{\mathrm{G}}$ and smaller bubble diameters due to the higher ionic strength [16].

The variations of residual $o$-cresol concentration in the effluent liquid $\left(\theta_{\mathrm{BLb}, \mathrm{eff}}\right)$ vs. the dimensionless ozonation time $(\tau)$ are shown in Fig. 3. It is seen that the prediction indicates a good agreement with the experimental data. The eliminating rate of $\theta_{\mathrm{BLb}, \mathrm{fff}}$ decreases with $\tau$ until reaching steady state. While the $\tau$ is greater than 5.0 , the values of $\theta_{\mathrm{BLb}, \text { eff }}$ are close to steady state of 0.335 and 0.896 for $u_{\mathrm{G} 0}=7.40$ and $1.33 \mathrm{~mm} / \mathrm{s}$, respectively. Furthermore, the corresponding applied ozone dosages $\left(=C_{\mathrm{AGi}} u_{\mathrm{G} 0} / u_{\mathrm{L}}\right)$ are 66.9 and $10.0 \mathrm{mg} O_{3(\mathrm{~g})} / L$ liquid for $u_{\mathrm{G} 0}=7.40$ and $1.33 \mathrm{~mm} / \mathrm{s}$, respectively. Accordingly, the ratios of the removal of $o$ cresol $(\mathrm{mg} / \mathrm{L})$ to the applied ozone dosage $(\mathrm{mg} / \mathrm{L})$ $\left(=C_{\mathrm{BLb} 0}\left(1-\theta_{\mathrm{BLb}, \mathrm{eff}}\right) u_{\mathrm{L}} /\left(C_{\mathrm{AGi}} u_{\mathrm{G} 0}\right)\right)$ at steady state are 1.08 and 1.12 for $u_{\mathrm{G} 0}=7.40$ and $1.33 \mathrm{~mm} / \mathrm{s}$, respectively. Thus, the case with the smaller $u_{\mathrm{G} 0}$ has a better utilization of ozone which agrees with the statement of Schulz and Prendiville [17]. As shown in Fig. 4, the predicted values of $\theta_{\mathrm{ALb} \text {,eff }}$ are smaller than 0.01 , which consists with the high consumption of liquid ozone accounting for the fast ozonation reaction regime [18]. Furthermore, the predicted value of $\theta_{\mathrm{ALb}, \text { eff }}$ for $u_{\mathrm{G} 0}=7.40 \mathrm{~mm} / \mathrm{s}$ increased from 0.0035 to 0.0082 with

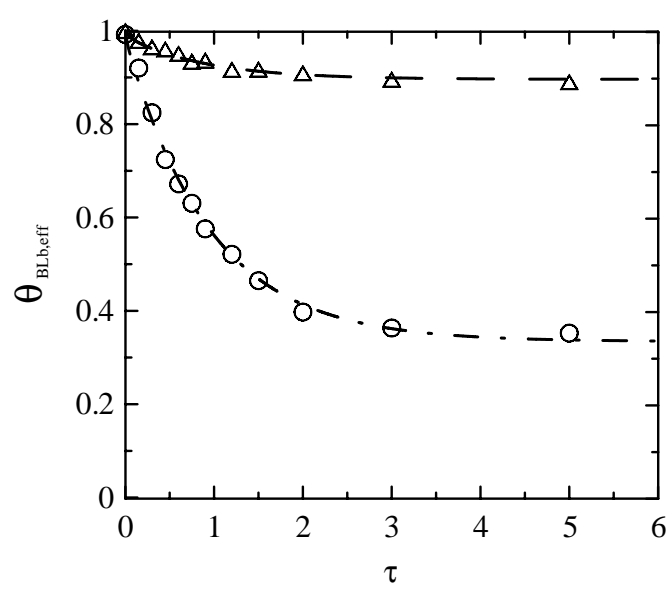

Fig. 3. Concentration variations of $\theta_{\mathrm{BLb}, \text { eff }}$ with $\tau$ for $o$-cresol ozonation in countercurrent bubble column. The conditions are the same as those in Fig. 2. Symbols, lines: experiments, prediction. $\bigcirc$ and,$--- \triangle$ and - - : $u_{\mathrm{G} 0}=7.40,1.33 \mathrm{~mm} /$ $\mathrm{s} ; R^{2}=0.992,0.985$.

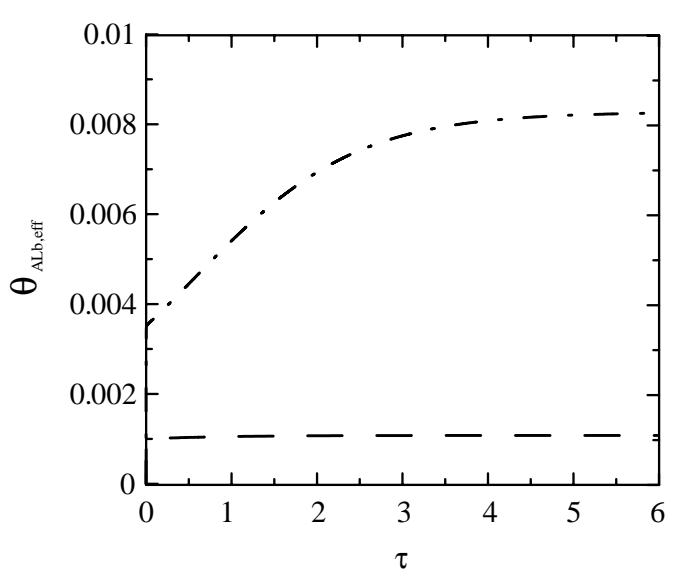

Fig. 4. Concentration variations of $\theta_{\mathrm{ALb} \text {,eff }}$ with $\tau$ for $o$-cresol ozonation in countercurrent bubble column. The conditions are the same as those in Fig. 2. Symbols, lines: experiments, prediction. - - - - - - : $u_{\mathrm{G} 0}=7.40,1.33 \mathrm{~mm} / \mathrm{s}$.

$\tau$ is higher than that for $u_{\mathrm{G} 0}=1.33 \mathrm{~mm} / \mathrm{s}$. The variation of $\theta_{\mathrm{ALb}, \text { eff }}$ with $\tau$ for $u_{\mathrm{G} 0}=1.33 \mathrm{~mm} / \mathrm{s}$ is insignificant with the average value of about 0.0011 . The values of the residual $\theta_{\mathrm{ALb}, \text { eff }}$ as low as $0.0035-0.0082$ or 0.0011 are so low as to be accurately measured. Thus, no accurate measurements of the extremely low $\theta_{\mathrm{ALb}, \text { eff }}$ have been available.

Base on the present model, the values of the enhancement factor of ozone $\left(E_{\mathrm{rA}}\right)$ and the retardation factor of oxygen $\left(R_{\mathrm{fO}}\right)$ for the gas-liquid mass transfer can be estimated. Due to the fast ozonation reaction rate, the mass transfer rate of ozone is enhanced significantly so that the $E_{\mathrm{rA}}$ value is greater than unit. 


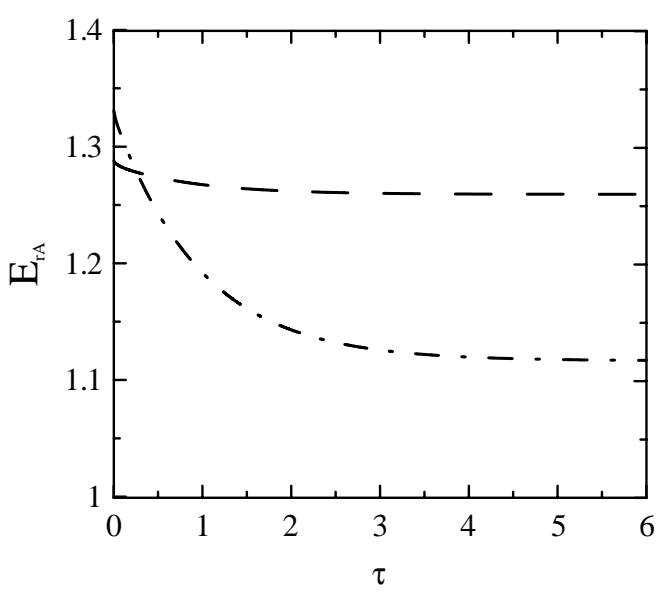

Fig. 5. Variations of $E_{\mathrm{rA}}$ at $z^{*}=0$ with $\tau$ for $o$-cresol ozonation in countercurrent bubble column. The conditions are the same as those in Fig. 2. Lines: prediction. - - - - - $u_{\mathrm{G} 0}=7.40$, $1.33 \mathrm{~mm} / \mathrm{s}$.

As shown in Fig. 5, the value of $E_{\mathrm{rA}}$ at $z^{*}=0$ decreases with $\tau$ significantly from the initial value of 1.33 to a constant value of 1.12 for $u_{\mathrm{G} 0}=7.40 \mathrm{~mm} / \mathrm{s}$. This is resulted from the remarkable decrease of $\theta_{\mathrm{BLb}}$ and increase of $\theta_{\mathrm{ALb}}$ with $\tau$. The value of $E_{\mathrm{rA}}$ at $z^{*}=0$ for $u_{\mathrm{G} 0}=1.33 \mathrm{~mm} / \mathrm{s}$ shows the slight decrease from 1.29 to 1.26. Further, the variation of $E_{\mathrm{rA}}$ can be reflected by the Hatta number of the ozonation reaction of pollutant $\left(H a_{\mathrm{B}}\right)$ defined as $\sqrt{k_{\mathrm{AB}} C_{\mathrm{BLb}} D_{\mathrm{A}}} / k_{\mathrm{LA}}^{0}$, which decreases from 0.74 to 0.25 and 0.69 to 0.62 at $z^{*}=0$ for $u_{\mathrm{G} 0}=$ 7.40 and $1.33 \mathrm{~mm} / \mathrm{s}$, respectively. As for the value of $R_{\mathrm{fO}}$, it is close to unity due to the small Hatta number of ozone self-decomposition reaction $\left(H a_{\mathrm{A}}\right)$, defined as $\sqrt{k_{\mathrm{d}} D_{\mathrm{A}}} / k_{\mathrm{LA}}^{0}$, with the value of about 0.003 in this study.

Fig. 6 compares the predicted values of the off-gas ozone concentration $\left(\theta_{\mathrm{AGe}}\right)$ with the experimental data, indicating the satisfactory agreement. The value of $\theta_{\mathrm{AGe}}$ increases rapidly in the early stage of $\tau<0.5$ and then gradually approaches the steady-state values of 0.038 and 0.002 for $u_{\mathrm{G} 0}=7.40$ and $1.33 \mathrm{~mm} / \mathrm{s}$, respectively. Note that the variation curves of $\theta_{\mathrm{AGe}}$ are similar to those of $\theta_{\mathrm{ALb}, \text { eff }}$. The variations of the outlet superficial gas velocity $\left(U_{\mathrm{G}, z^{*}=1}\right)$, which represents the amount of the off-gas, are depicted in Fig. 7. It can be noted that the value of $U_{\mathrm{G}}$ along $z^{*}$ increases with the hydrostatic pressure the term of $\left(\alpha_{\mathrm{P}} / \beta_{\mathrm{P}}\right) U_{\mathrm{G}}$, while decreases with the gas-liquid mass transfer terms of ozone and oxygen as shown in Eq. (13). The steady-state values of $U_{\mathrm{G}, z^{*}=1}$ in Fig. 7 are greater than unit, indicating that the effect of the variation of the hydrostatic pressure term on $U_{\mathrm{G}}$ is more significant than that of the mass transfer terms. The value of $U_{\mathrm{G}, z^{*}=1}$ can be employed to compute the ozone transfer efficiency $\left(\eta_{\text {OTE }}\right)$ and the specific transferred ozone dosage $\left(m_{\mathrm{STOD}}\right)$. The $\eta_{\mathrm{OTE}}\left(=1-U_{\mathrm{G}, z^{*}=1}\right.$ $\left.\theta_{\mathrm{AGi}, z^{*}=1}\right)$ and $m_{\mathrm{STOD}}\left(=C_{\mathrm{AGi} 0} u_{\mathrm{G} 0} \eta_{\mathrm{OTE}} / u_{\mathrm{L}}\right)$ are defined

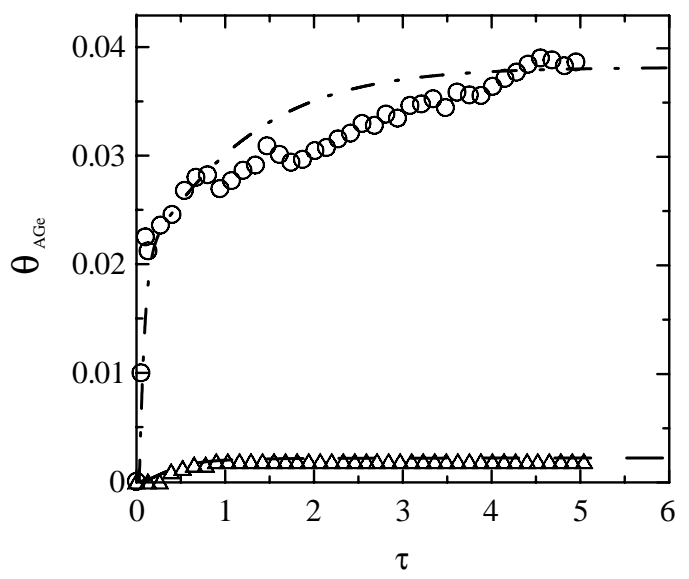

Fig. 6. Concentration variations of $\theta_{\mathrm{AGe}}$ with $\tau$ for $o$-cresol ozonation in countercurrent bubble column. The conditions are the same as those in Fig. 2. Symbols, lines: experiments, prediction. $\bigcirc$ and,$-- \triangle$ and - $: u_{\mathrm{G} 0}=7.40,1.33 \mathrm{~mm} / \mathrm{s}$.

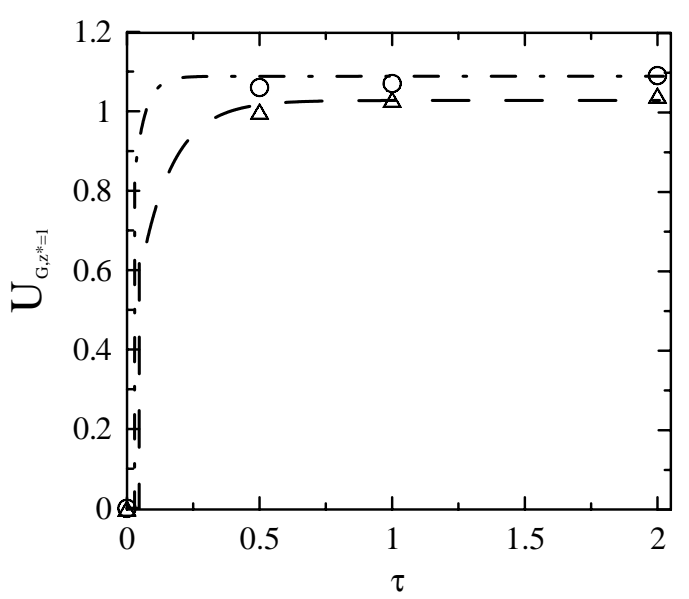

Fig. 7. Variations of $U_{\mathrm{G}, z^{*}=1}$ with $\tau$ for $o$-cresol ozonation in countercurrent bubble column. The conditions are the same as those in Fig. 2. Symbols, lines: experiments, prediction. $\bigcirc$ and - -,$\triangle$ and ——: $u_{\mathrm{G} 0}=7.40,1.33 \mathrm{~mm} / \mathrm{s}$.

as the percentage of the inlet ozone transferred into the target water and the ratio of the transferred ozone to the target water volume, respectively. Based on the predicted results, the steady-state values of $\eta_{\text {OTE }}$ and $m_{\mathrm{STOD}}$ are 0.959 and $64.1 \mathrm{mg} / \mathrm{L}$, and 0.998 and $9.99 \mathrm{mg} / \mathrm{L}$ for $u_{\mathrm{G} 0}=7.40$ and $1.33 \mathrm{~mm} / \mathrm{s}$, respectively. The values of $\eta_{\text {OTE }}$ are obviously higher than those obtained from the ozone dissolution experiments in the same apparatus of Chen et al. [7] due to the higher reactivity of the solution. It may be worth mentioning that the steadystate values of $C_{\mathrm{BLb} 0}\left(1-\theta_{\mathrm{BLb}, \mathrm{eff}}\right) / m_{\mathrm{STOD}}$ for the cases with $u_{\mathrm{G} 0}=7.40$ and $1.33 \mathrm{~mm} / \mathrm{s}$ are almost identical, verifying the consistency of the mass balance of the model prediction and experiment data. 
In addition, the effect of neglecting oxygen mass transfer on the ozonation simulation is examined. The result indicates that the differences of the predicted values of $\theta_{\mathrm{ALb}, \text { eff }}, \theta_{\mathrm{AGe}}, \theta_{\mathrm{BLb}, \text { eff }}$ and $E_{\mathrm{rA}}$ with and without considering the oxygen mass transfer are insignificant with the relative deviation of less than $3 \%$. Therefore, one may propose that the oxygen mass transfer may be neglected for evaluating the values of $\theta_{\mathrm{ALb}, \text { eff }}, \theta_{\mathrm{AGe}}$, $\theta_{\mathrm{BLb}, \text { eff }}$ and $E_{\mathrm{rA}}$. However, it should be noted that information about the dissolved oxygen concentration is thus not available assuming the oxygen as an inert gas.

\subsection{Simulation of dynamic processes of ozonation}

To characterize the hydrodynamics of the column, the modeling value of $P e_{\mathrm{L}}$ is taken as 10.0 for the typical value [19] in the following simulation while the other

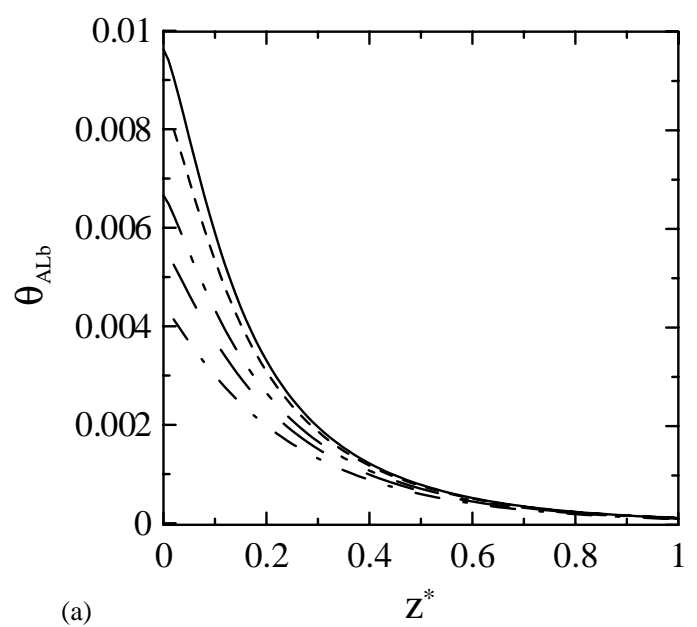

(a)

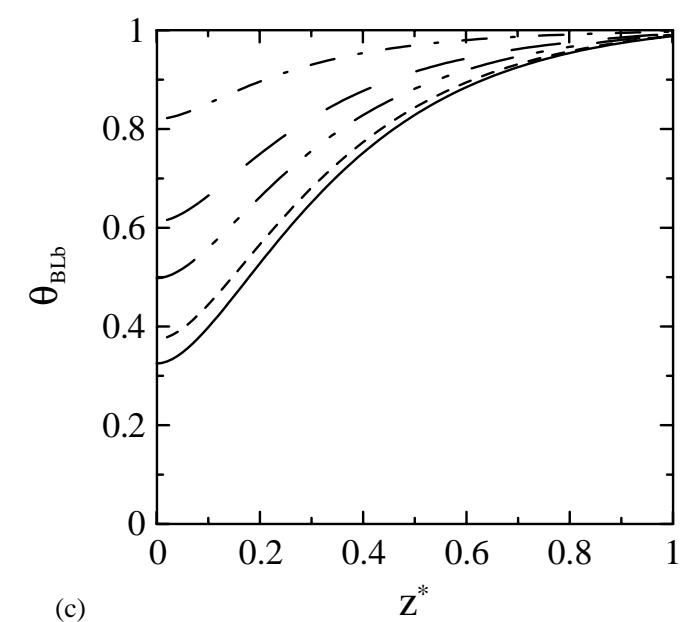

conditions are the same as those specified in Fig. 2 for $u_{\mathrm{G} 0}=7.40 \mathrm{~mm} / \mathrm{s}$. The predicted profiles of $\theta_{\mathrm{ALb}}, \theta_{\mathrm{AGi}}$, $\theta_{\mathrm{BLb}}$, and $E_{\mathrm{rA}}$ as a function of the dimensionless axial coordinate $z^{*}$ and the ozonation time $\tau$ are shown in Fig. 8. It is seen that the shapes of the profiles at $\tau=0.1$, $0.3,0.5$, and 1.0 of the transient state resemble those in the regime of steady state. The values of $\theta_{\mathrm{ALb}}$ and $\theta_{\mathrm{AGi}}$ decrease monotonically with $z^{*}$ along the column which is qualitatively similar to the circumstance with ozone self-decomposition alone studied by Chen et al. [2]. Thus, the maximum values of $\theta_{\mathrm{ALb}}$ and $\theta_{\mathrm{AGi}}$ appear at the bottom of the column. In addition, the concentration profile of $\theta_{\mathrm{AGi}}$ approaches steady state faster comparing with that of $\theta_{\mathrm{ALb}}$.

On the other hand, the values of $\theta_{\mathrm{BLb}}$ and $E_{\mathrm{rA}}$ increase with $z^{*}$ from the bottom to the top. The value of $\theta_{\mathrm{BLb}}$ decreases apparently while the liquid flows downwards
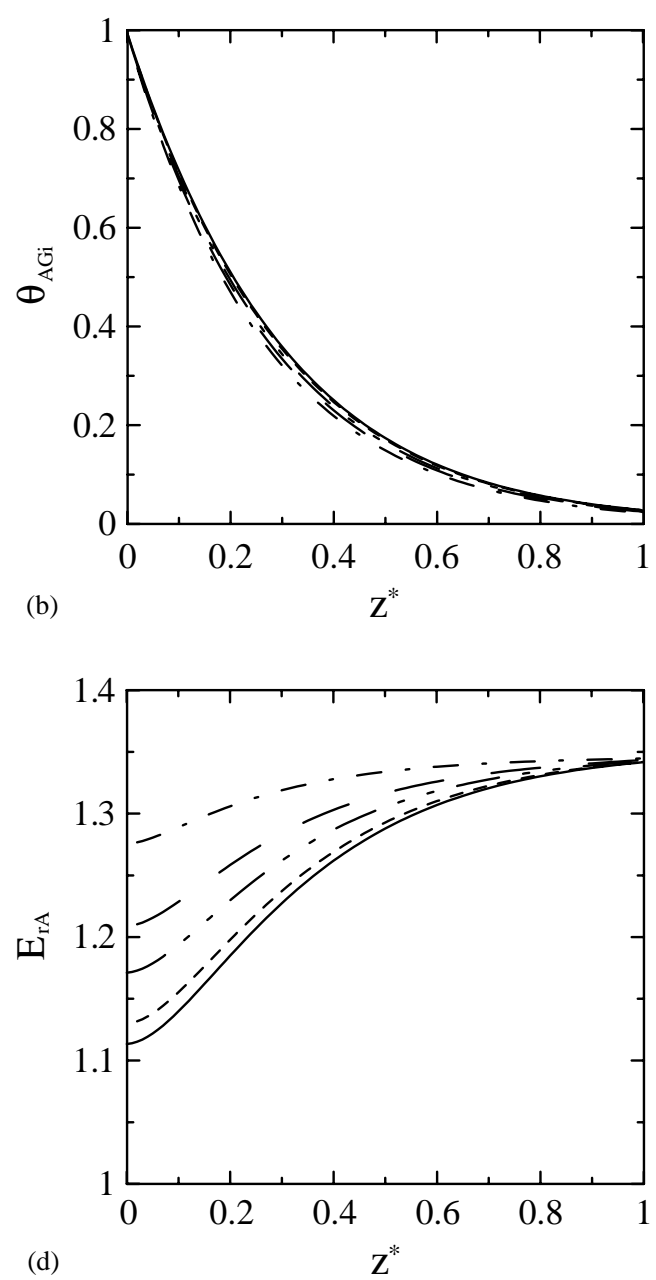

Fig. 8. Variations of concentrations and $E_{\mathrm{rA}}$ with $z^{*}$ at different $\tau$ for ozonation in countercurrent bubble column. $P e_{\mathrm{L}}=10.0$, while other conditions are the same as those in Fig. 2 for $u_{\mathrm{G} 0}=7.40 \mathrm{~mm} / \mathrm{s}$. Lines: prediction. — - —, — - - - - - - - - - - -, and $\tau=0.1,0.3,0.5,1.0$, and steady state. (a) $\theta_{\mathrm{ALb}}$, (b) $\theta_{\mathrm{AGi}}$, (c) $\theta_{\mathrm{BLb}}$, and (d) $E_{\mathrm{rA}}$. 
near the bottom of the column owing to the higher value of $\theta_{\mathrm{ALb}}$. Therefore, the minimum value of $\theta_{\mathrm{BLb}}$ would occur in the effluent liquid. The profiles of $E_{\mathrm{rA}}$ resemble to those of $\theta_{\mathrm{BLb}}$ indicating that the value of $E_{\mathrm{rA}}$ significantly depends on $\theta_{\mathrm{BLb}}$. Therefore, the dynamic and axial variations of $\theta_{\mathrm{ALb}}, \theta_{\mathrm{AGi}}, \theta_{\mathrm{BLb}}$, and $E_{\mathrm{rA}}$ in the column should be considered properly for depicting the ozonation system.

To show the effects of dimensionless parameters on the ozonation performance, the concerned variables at steady state with various levels of $P e_{\mathrm{L}}, D a_{\mathrm{AB}}$, and $k_{\mathrm{LO}}^{0} a$ are summarized, respectively, in Table 1. As the $P e_{\mathrm{L}}$ increases, the values of $\theta_{\mathrm{ALb}, \text { eff }}, \theta_{\mathrm{OLb}, \text { eff }}, E_{\mathrm{rA} \text {,avg }}$ and $\eta_{\mathrm{OTE}}$ increase while the $\theta_{\mathrm{ALb} \text {,avg }}$ and $\theta_{\mathrm{BLb} \text {,eff }}$ decrease. It means that the approach of hydrodynamic characteristics to plug flow with higher concentration gradients of $\theta_{\mathrm{ALb}}$ and $\theta_{\mathrm{BLb}}$ is advantageous to the gas-liquid mass transfer and the removal efficiency of pollutant. The results agree with the study of Le Sauze et al. [20] who compared the ozone transfer efficiency of reactors with different mixing degree. Regarding the variation of $D a_{\mathrm{AB}}$ adjusted by the value of $k_{\mathrm{AB}}$, one can see that it remarkably affects most system variables with the exception of $\theta_{\mathrm{OLb}, \mathrm{eff}}$. The values of $\theta_{\mathrm{ALb}, \mathrm{eff}}, \theta_{\mathrm{ALb}, \text { avg }}$ and $\theta_{\mathrm{BLb}, \text { eff }}$ decrease while those of $E_{\mathrm{rA} \text {,avg }}$ and $\eta_{\mathrm{OTE}}$ increase as the $D a_{\mathrm{AB}}$ is enhanced. Accordingly, the reaction rate of pollutant ozonation is an important factor for assessing the treatment efficiency of an ozonation system. The avenue to enlarge the reaction rate constant is favorable for the utilization of the feed ozone and the elimination of the pollutant. Note that the effects of Stanton numbers are reflected by the $k_{\mathrm{LO}}^{0} a$ as they are proportional to $k_{\mathrm{LO}}^{0} a$. As indicated in Table 1 , the values of $\theta_{\mathrm{ALb} \text {,eff }}$ and $\theta_{\mathrm{OLb} \text {,eff }}$ clearly increase correlated with the higher $\eta_{\text {OTE }}$ and removal efficiency of pollutant as the $k_{\mathrm{LO}}^{0} a$ increases.

In addition, the effects of these dimensionless parameters on the time required for the establishment of steady state are examined. It is found that the ozonation processes reach steady state faster with higher values of the Peclet, Damköhler, and Stanton numbers. For instance, the variations of $\theta_{\mathrm{BLb}}^{*}\left(=\left(C_{\mathrm{BLb}}-C_{\mathrm{BLb}, \mathrm{ss}}\right) /\right.$
$\left.\left(C_{\mathrm{BLb} 0}-C_{\mathrm{BLb}, \mathrm{ss}}\right)\right)$ in the effluent liquid, which has the initial value of unit and the steady-state value of zero, with $\tau$ at various values of $P e_{\mathrm{L}}$ are shown in Fig. 9. The value of $\theta_{\mathrm{BLb}}^{*}$ with higher $P e_{\mathrm{L}}$ value takes shorter ozonation time to reach zero. The observation has similarities with the results of the circumstance with ozone self-decomposition alone studied by Chen et al. [7]. The bubble column under the conditions of this study is allowed to stabilize for about 2-5 hydraulic retention times $\left(t_{\mathrm{L}}\right)$ after the ozone gas was started. However, this time scale for reaching steady state is usually longer than that for the circumstance with ozone self-decomposition alone ranging from about 1.5 to $3 t_{\mathrm{L}}$. All the results obtained here show that the DADM proposed in this study is useful for the prediction and description of the dynamic ozonation processes in a countercurrent bubble column.

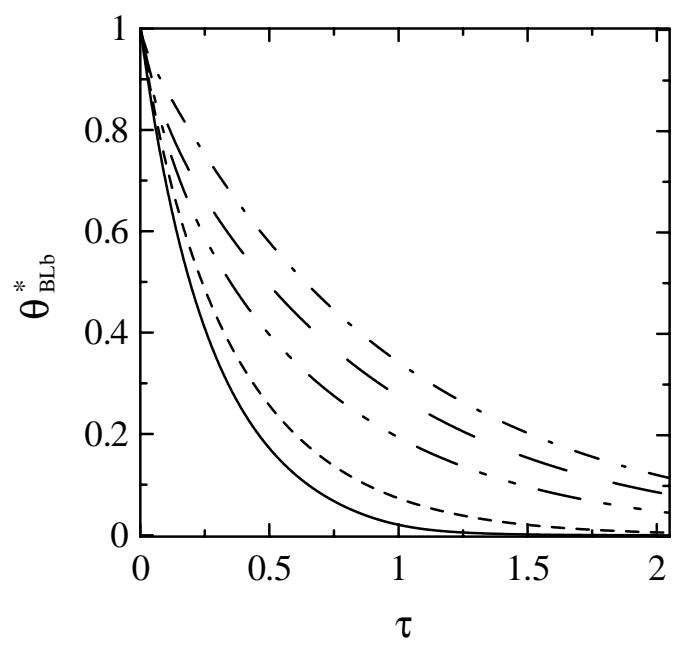

Fig. 9. Variations of $\theta_{\mathrm{BLb}}^{*}$ in effluent liquid vs. $\tau$ at various values of $P e_{\mathrm{L}}$ for ozonation in countercurrent bubble column. The conditions are the same as those in Fig. 2 for $u_{\mathrm{G} 0}=7.40 \mathrm{~mm} / \mathrm{s}$ except the $P e_{\mathrm{L}}$ value. Lines: prediction. - -

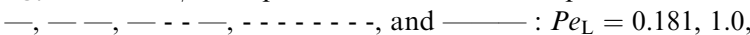
$2.5,10,100$.

Table 1

Summary of values of system variables at steady state with various levels of $P e_{\mathrm{L}}, D a_{\mathrm{AB}}$ and $k_{\mathrm{LO}}^{0} a$

\begin{tabular}{|c|c|c|c|c|c|c|c|c|c|c|c|c|c|c|c|}
\hline \multirow[t]{2}{*}{ System variable } & \multicolumn{5}{|l|}{$P e_{\mathrm{L}}$} & \multicolumn{5}{|l|}{$D a_{\mathrm{AB}}$} & \multicolumn{5}{|c|}{$k_{\mathrm{LO}}^{0} a\left(\mathrm{~s}^{-1}\right)$} \\
\hline & 0.181 & 1 & 2.5 & 10 & 100 & 10 & 100 & 1000 & 7177 & $10^{5}$ & 0.01 & 0.02 & 0.05 & 0.075 & 0.1 \\
\hline$\theta_{\mathrm{ALb}, \mathrm{eff}}$ & 0.0083 & 0.0090 & 0.0093 & 0.0096 & 0.0099 & 0.702 & 0.298 & 0.054 & 0.010 & 0.001 & 0.0007 & 0.0016 & 0.0057 & 0.0096 & 0.0132 \\
\hline$\theta_{\mathrm{ALb}, \mathrm{avg}}$ & 0.0028 & 0.0025 & 0.0023 & 0.0019 & 0.0017 & 0.446 & 0.102 & 0.013 & 0.002 & 0.000 & 0.0004 & 0.0008 & 0.0016 & 0.0019 & 0.0021 \\
\hline$\theta_{\mathrm{BLb}, \mathrm{eff}}$ & 0.334 & 0.331 & 0.328 & 0.325 & 0.319 & 0.658 & 0.412 & 0.350 & 0.325 & 0.302 & 0.737 & 0.577 & 0.373 & 0.325 & 0.310 \\
\hline$\theta_{\mathrm{OLb}, \mathrm{eff}}$ & 0.951 & 0.979 & 0.988 & 0.994 & 0.997 & 0.992 & 0.993 & 0.994 & 0.994 & 0.996 & 0.907 & 0.970 & 0.990 & 0.994 & 0.996 \\
\hline$E_{\mathrm{rA}, \mathrm{avg}}$ & 1.13 & 1.17 & 1.21 & 1.26 & 1.28 & 1.00 & 1.01 & 1.04 & 1.26 & 3.43 & 1.29 & 1.27 & 1.25 & 1.26 & 1.27 \\
\hline$\eta_{\mathrm{OTE}}$ & 0.958 & 0.963 & 0.967 & 0.971 & 0.972 & 0.602 & 0.889 & 0.942 & 0.971 & 1.000 & 0.383 & 0.612 & 0.904 & 0.971 & 0.991 \\
\hline
\end{tabular}




\section{Conclusions}

1. The present dynamic axial dispersion model is rigorous, considering hydrodynamic behavior, ozone and oxygen mass transfers, and ozonation reactions simultaneously. The dynamic variations of the ozone, pollutant, and oxygen concentration profiles can be well predicted from the beginning to steady state.

2. After the introduction of ozone gas was started, the dissolved concentrations of ozone and oxygen and the amount of the off-gas increase with ozonation time $(t)$, while the pollutant concentration and the enhancement factor of ozone decrease with $t$. The bubble column is allowed to stabilize for about 2-5 hydraulic retention times in this study.

3. The gas and liquid concentrations of ozone decrease monotonically with the axial coordinate $(z)$ from the bottom to the top of column, while the pollutant concentration and the enhancement factor of ozone increase with $z$. The patterns of profile curves of these variables in the transient state are similar to those in steady state.

4. The oxygen mass transfer may be neglected for simulating the ozonation processes with the slight difference $(<3 \%)$ of the prediction of residual ozone and pollutant concentrations. However, the information about dissolved oxygen concentration, which clearly increases due to ozonation processes, is not available assuming oxygen as an inert gas.

5. The ozonation system with higher values of Peclet, Damköhler, and Stanton numbers is favorable for the utilization of feed ozone and the removal efficiency of pollutant. Furthermore, the time required for the establishment of steady state can be reduced by increasing the values of Peclet, Damköhler, and Stanton numbers.

\section{Acknowledgements}

This study was support by the National Science Council of Taiwan under Grant No. NSC 91-2211-E002-105.

\section{References}

[1] Deckwer WD, Schumpe A. Improved tools for bubble column reactor design and scale-up. Chem Eng Sci 1993;48(5):889-911.

[2] Chen YH, Chang CY, Chiu CY, Yu YH, Chiang PC, Ku $\mathrm{Y}$, Chen JN. A dynamic model of ozone disinfection in a bubble column with oxygen mass transfer. J. Chin Inst Chem Eng 2002;33(3):253-65.
[3] Zhou H, Smith DW, Stanley SJ. Modeling of dissolved ozone concentration profiles in bubble columns. J Environ Eng 1994;120(4):821-40.

[4] Beltrán FJ, González M, Acedo B, Rivas FJ. Kinetic modelling of aqueous atrazine ozonation processes in a continuous flow bubble contactor. J Hazard Mater 2000;80(1-3):189-206.

[5] Chiang PC, Ko YW, Liang CH, Chang EE. Modeling an ozone bubble column for predicting its disinfection efficiency and control of DBP formation. Chemosphere 1999;39(1):55-70.

[6] El-Din MG, Smith DW. Designing ozone bubble columns: a spreadsheet approach to axial dispersion model. Ozone Sci Eng 2001;23(5):369-84.

[7] Chen YH, Chang CY, Chiu CY, Huang WH, Yu YH, Chiang PC, Ku Y, Chen JN. Dynamic model of ozone contacting process with oxygen mass transfer in bubble columns. J Environ Eng 2002;128(11):1036-45.

[8] Danckwerts PV. Gas-liquid reactions, 1st ed. New York, NY, USA: McGraw-Hill, 1970.

[9] Chang CY, Chen YH, Li H, Chiu CY, Yu YH, Chiang $\mathrm{PC}, \mathrm{Ku} \mathrm{Y}$, Chen JN. Kinetics of decomposition of polyethylene glycol in electroplating solution by ozonation with UV radiation. J Environ Eng 2001;127(10):908-15.

[10] Mariñas BJ, Liang S, Aieta EM. Modeling hydrodynamics and ozone residual distribution in a pilot-scale ozone bubble-diffuser contactor. J AWWA 1993;85(3):90-9.

[11] Kaštánek F, Zahradník J, Kratochvíl J, Črmák J. Chemical reactors for gas-liquid systems, 1st ed. New York, NY, UAS: Ellis Horwood, 1993.

[12] Deckwer WD. Bubble column reactor, 1st ed. New York, NY, USA: Wiley, 1992.

[13] Hoigné J, Bader H. Rate constants of reactions of ozone with organic and inorganic compounds in water. Water Res 1983;17:173-83.

[14] Beltrán FJ, Encinar JM, Garcia-Araya JF. Ozonation of $o$ cresol in aqueous solutions. Water Res 1990;24(11): 1309-16.

[15] Sotelo JL, Beltrán FJ, Benítez FJ, Beltrán-Heredia J. Ozone decomposition in water: kinetic study. Ind Eng Chem Res 1987;26(1):39-43.

[16] Feng DW, Aldrich C. Effect of fluid properties on twophase froth characteristics. Ind Eng Chem Res 1999;38(10):4110-2.

[17] Schulz CR, Prendiville PW. Designing high-concentration ozone contactors for drinking-water treatment plants. Ozone Sci Eng 1993;15(3):245-66.

[18] Beltrán FJ, Garcia-Araya JF, Rivas FJ, Álvarez P, Rodríguez E. Kinetics of competitive ozonation of some phenolic compounds present in wastewater from food processing industries. Ozone Sci Eng 2000;22(2):167-83.

[19] Martin N, Boisdon V, Laplanche A, Uhlig P. Modelization of industrial ozonation tanks: a useful tool for the design of $2000 \mathrm{~s}$ ozone reactor. Water Supply 1995;13(2):57-74.

[20] Le Sauze N, Laplanche A, Martin N, Martin G. Modelling of ozone transfer in a bubble column. Water Res 1993;27(6):1071-83. 